\title{
PROFESSORAS DA EDUCAÇÃO DE JOVENS E ADULTOS REENCANTADAS PELA EDUCAÇÃO E SEU ENREDAMENTO NAS PRÁTICAS DA EDUCAÇÃO AMBIENTAL
}

Nadja Valéria dos Santos Ferreira ${ }^{1}$

Resumo: O objetivo deste trabalho é apresentar uma pesquisa que procurou compreender as marcas de repertórios identitários-culturais relacionados à Educação Ambiental presentes nas práticas e narrativas de professoras da Educação de Jovens e Adultos (EJA), de uma escola municipal do Distrito de Xerém (Duque de Caxias/RJ). A cartografia dessas marcas nos remete à produção de sentidos de um processo complexo de autoformação coletiva em redes de contextos que levam à compreensão de que a Educação Ambiental se apresenta em qualquer processo educativo em que haja estreita relação entre a realidade vivida por alunos praticantes e a estruturação de atividades por professores e professoras em torno de problemas concretos da comunidade e, ainda, que a construção de novos saberes está intimamente relacionada à atitude docente de reencantamento pela educação..

Palavras-chave: Autoformação Docente; Cartografia; Educação Ambiental; Narrativas. Universidade do Estado do Rio de Janeiro (UERJ) atuando no Instituto de Aplicação Fernando Rodrigues da Silveira - CAp-UERJ. E-mail: nadjaval@gmail.com

Revbea, São Paulo, V. 12, № 2: 274-283, 2017. 


\section{Introdução}

Este trabalho apresenta uma experiência que aponta para a possibilidade de uma formação docente continuada / contínua, diferenciada em Educação Ambiental, tecida cotidianamente e de forma coletiva, que envolve professoras que atuam com jovens e adultos que tem como lócus uma escola pública do Distrito de Xerém (RJ). É uma história que apresenta questões pedagógicas tratadas como desafios a serem resolvidos no coletivo, no diálogo, culminando na formulação de uma prática pedagógica construída de forma processual na qual os ensinamentos de Paulo Freire - quando destaca a importância de um professor crítico, que parta dos saberes de seus alunos e estimule sua curiosidade -, estão sempre presentes na prática docente de forma vívida/vivenciada.

O viés Meio Ambiente presente nas práticas socioeducativas dessas educadoras permite analisar a realidade, ultrapassando o caráter meramente conceitual, visto que a Educação ambientalmente comprometida é a que pressupõe procedimentos e atitudes por parte do sujeito. Ao estimularem que seus/suas educandas jovens e adultos/as enfoquem os problemas locais, para conseguir ampliar para o global, se alinham ao afirmado na Conferência Intergovernamental de Tbilisi (UNESCO, 1997), realizada na cidade de mesmo nome na Geórgia (ex-URSS) no ano de 1977, que destacou que os comportamentos cotidianos deste público podem ter uma influência decisiva na preservação e melhoria do meio ambiente.

Esta pesquisa incorpora a perspectiva da complexidade, no sentido de exercitar outras formas de apreender a realidade "calcadas na multiplicidade de interpretações e produzidas no entrelaçamento das diferentes perspectivas, dos diferentes sujeitos, nos diferentes contextos da vida cotidiana" (PÉREZ, 2003, p.98).

A narrativa é trazida em suas diferentes formas - oral, escrita e imagética - para registrar, de alguma forma, as práticas socioambientais presentes no trabalho docente para aprofundar a discussão sobre o quanto a singularidade e a coletividade do olhar são preciosas em qualquer proposta formativa.

\section{Cartografando: o viés metodológico da pesquisa}

Para atender a necessidade de aproximação com o provável futuro leitor procuro neste trabalho apresentar uma fotografia do local em que os diversos sujeitos-praticantes vivem, (re) vivem, convivem, mostrando a tensividade (PASSOS; SATO, 2002) existente nas relações entre os sujeitos-praticantes dada a diversidade humana -, a qual só pode ser recuperada pelo diálogo amoroso a partir da compreensão de que vivemos em um mesmo planeta.

Duque de Caxias é um dos municípios que compõem a Baixada Fluminense, região caracterizada pela grande concentração de bolsões de pobreza e carente de infraestrutura básica. Subdivide-se em quatro distritos,

revista brasileira educação ambiental 
sendo Xerém o maior, que possui uma extensa área de Mata Atlântica ainda preservada e convive com o paradoxo de apresentar simultaneamente características rurais e urbanas, tanto em termos socioeconômicos quanto em termos socioculturais o que nos aproxima do pensamento de Morin (2007) quando destaca que a relação antropossocial é complexa. O mesmo ocorre em relação aos movimentos culturais, pois convivem, no referido distrito, expressões tradicionais como a folia de reis, e as chamadas "vaquejadas fest" que desconsidera as características da comunidade local, em nome de ganhos socioeconômicos.

Para produzir sentidos torna-se importante contextualizar os espaçostempos enfocados nesta pesquisa, apresentar os seus sujeitos e identificar o lugar que ocupam nesta história, que foi tecida a partir de informações incorporadas pouco a pouco, desvelando suas táticas de sobrevivência que remontam à perspectiva dos movimentos instituintes do espaço escolar público (LINHARES ,2002, p.18), quando destaca "que estes movimentos e as experiências deles decorrentes, estouram nos mais diferentes espaçostempos da vida". Por meio destes movimentos as professoras procuram tornar o aprender, para os jovens e adultos, uma tarefa prazerosa e significativa, na medida em que resgatam o sentido do conhecimento como potência.

Como orientação e suporte narrativo é trazido o filme "Narradores de Javé (BRASIL, 2003), cujos personagens e diálogos se aproximam das reflexões trazidas pelos sujeitos narradores de Xerém. Em suas relações cotidianas, assim como em Javé, apresentam-se lideranças que procuram mobilizar a comunidade a refletir sobre os problemas socioambientais e a crescente degradação ambiental realizando encontros e seminários temáticos de Educação Ambiental, como o $2^{\circ}$ Seminário realizado em $2008^{2}$, que se voltou à discussão da possível ida do lixão de um município vizinho para aquela área de Mata Atlântica.

Destacam-se, então, os moradores antigos que começam a contar os "causos" significativos que reportam para o ontem justificando, muitas vezes, ações do presente, permitindo antever o futuro.

Em áreas com características semelhantes à de Xerém, na qual convivem o rural e o urbano, a preservação e o progresso, a Escola tende a atrair para si as discussões e problemas locais o que se potencializa ainda mais quando atende à modalidade de ensino educação de jovens e adultos (EJA). Percebe-se, que neste caso, a contextualização do vivido se reflete nas atividades pedagógicas propostas pelas docentes a estes educandos e educandas.

A opção metodológica que se ajusta a este caminhar é a Cartografia, não apenas pelo que comumente se traduz como sendo sua funcionalidade, mas partilhando da perspectiva de Sousa Santos (2007a) de que o mapa é

\footnotetext{
2 Destinação do Lixo no Município de Duque de Caxias: Alternativas e Soluções

Revbea, São Paulo, V. 12, № 2: 274-283, 2017.
} 
uma distorção regulada não-caótica da realidade, uma metáfora cultural ${ }^{3}$, o que permitirá compreender que não estarão sendo apresentados apenas fatos históricos ou espaços geográficos, mas uma narração que parte de um olhar/observação que vai para além do sujeito individual, por ter sido produzida por e junto a sujeitos sociais.

Este trabalho também assume a perspectiva da justiça social/ambiental daquilo que Sousa Santos define como "injustiça cognitiva global" a exigir a construção de um novo pensamento. O local escolhido para focar este trabalho permite este caminhar, pois, percebe-se no município de Duque de Caxias clara tensão entre a regulação e a emancipação social.

$O$ ensino para jovens e adultos na região tem se ampliado com a vinda de pessoas adultas de outros estados do Brasil, principalmente Minas Gerais e Bahia, com pouca ou nenhuma experiência escolar, para atender a um polo petroquímico que vai se ampliando. Estes sujeitos se configuram em pessoas de certa forma desterritorializadas que parecem ter pouco vínculo com seus locais de origem, o que tem exigido que as docentes criem, e procuram fazê-lo de forma coletiva, práticas pedagógicas que valorizem identidades e tradição culturais (Hall, 2006) para conseguir empoderá-los de forma cidadã.

\section{Dialogando para criar um movimento instituinte de autoformação coletiva}

A formação de professores, como já afirmava Freire (2003), não é um trabalho solitário. Freire já destacava que o ser humano se constitui no coletivo e que a aprendizagem deve ser fruto do diálogo do sujeito consigo mesmo e com os outros. Certeau (2008) afirma que a formação consiste em fazer um lugar para a autoformação das pessoas reunindo as artes de fazer cotidianas.

Entendo, a partir destas ideias que o que vem ocorrendo com as professoras é um movimento instituinte de autoformação coletiva porque reúne um grupo de docentes em sintonia, preocupadas com a efetivação do processo ensino-aprendizagem de pessoas jovens e adultas que procuram partir do saber acumulado de seus educandos e educandas para criar uma prática pedagógica consistente que os/as leve a uma situação de protagonistas conscientes de seu papel no planeta. Há, em seus saberesfazeres o que podemos definir como sinergia ambiental no sentido de busca do equilíbrio entre as ações, que procuram ser coordenadas e integradas com um objetivo comum explícito para educadores e educandos.

Percebe-se que o processo educativo que enfocamos é Educação Ambiental por haver relação estreita com a realidade vivida pelos sujeitos praticantes já que as atividades vão sendo estruturadas em torno dos problemas concretos da comunidade e se procura compreendê-los de forma global em busca de soluções construídas coletivamente construindo saberes, reconstruindo-os e ampliando-os. É, portanto, um processo de renovação

\footnotetext{
${ }^{3}$ Konvitz (1980, citado por BOAVENTURA SANTOS, 2007, p. 200).
}

revista brasileira educação ambiental 
permanente de métodos e conteúdos, "um saber sempre adaptado às condições variáveis do meio ambiente" (Tbilisi - Recomendação no 1).

Alves e Garcia (2008, p.74-75) alertam para que estejamos atentos ao cotidiano escolar quando afirmam:

Aqueles que têm estudado o cotidiano da escola - e da vida sabem, no entanto, que as vozes, nos projetos dominantes, proibidas de falar, continuam falando; os sons interditados que nele circulam são ouvidos por alguém, os cheiros aí produzidos chegam a algum lugar. De maneira caótica, como na vida, nos cotidianos das escolas continuam a ser tecidas redes sem começo nem fim e que, como nos ensina Prigogine, do tão negado e temido caos pode emergir uma nova organização. $E$ é isto que tanto assusta os que detêm o poder e que tanto se aferram à ordem.

Esta fala aponta para a necessidade de ouvir as vozes da comunidade escolar, por muito tempo desqualificadas, pois estas darão pistas para que compreendamos sua configuração atual e a crise porque passa a Escola ao não conseguir, com qualidade, cumprir sua missão de ensino e aprendizagem. Uma destas importantes vozes é a do docente, que, principalmente em relação ao que lhe é oferecido como formação, quase não é ouvida. Especificamente em relação à formação do professor da Educação de Jovens e Adultos, percebe-se quase que um abandono político-institucional.

As docentes, na pesquisa desenvolvida, não se conformam com este abandono e procuram direcionar sua prática para o conhecimento que seu educando traz, impregnado de valores, crenças pessoais, modos de viver e ver a vida. É uma ação que se aproxima da visão analítica de Sousa Santos (2007b) quando fala da Sociologia das Ausências como um "procedimento transgressivo, uma sociologia insurgente, para tentar mostrar que o que não existe é produzido ativamente como não-existente, como uma alternativa nãocrível, como uma alternativa descartável, invisível à realidade hegemônica do mundo" (p.29-30). Parte do que ele denomina monocultura do saber e do rigor, que ignora as práticas sociais baseadas em conhecimentos populares, indígenas, camponeses, urbanos.

Ao não desvalorizar estes saberes, mas, ao contrário, procurar partir deles para a tessitura de novos o professor está utilizando uma tática que resulta da astúcia, e só é possível a quem se coloca na posição de aprender com o aluno, abrindo mão do poder que a posição de docente the confere. Pode ser vista como a tática da qual fala Certeau (2008, p. 46-47): 
um cálculo que não pode contar com um próprio, nem, portanto com uma fronteira que distingue o outro como totalidade visível. A tática só tem por lugar o do outro. [...]. Ao contrário, pelo fato de seu não-lugar, a tática depende do tempo, vigiando para "captar no voo" possibilidades de ganho. O que ela ganha não o guarda. Tem constantemente que jogar com os acontecimentos para transformá-los em "ocasiões".

Neste momento se apresenta a Educação Ambiental como uma possibilidade de permitir que o sujeito-estudante se perceba legitimado pela prática docente que foge ao instituído, configurada em uma reorganização rápida dos espaços, uma ação quase sub-reptícia que aproveita sutilmente as falhas e fissuras no processo que parte da discussão local para chegar ao global, do conhecido para o desconhecido, de forma inter/transdisciplinar, humanizadora e transversalizante.

Selecionar conteúdos a partir de saberes fragmentados (disciplinas) e realizar esta seleção a partir de critérios que, embora busquem o que é conveniente aos que vão aprender, os exclui desta escolha, é a visão dos que trabalham para uma escola e alunos ideais, para uma sociedade idealizada por detentores do poder ansiosos por manter seu status quo. São duas características que mostram a importância da escola atual utilizar táticas transgressoras, se efetivamente, se propõe a assumir o projeto de humanização do homem defendido por Paulo Freire (2003, p.31), o projeto de um verdadeiro educador ambiental, o que fica claro no trecho abaixo:

Por que não aproveitar a experiência que têm os alunos de viver em áreas da cidade descuidadas pelo poder público para discutir, por exemplo, a poluição dos riachos e dos córregos e os baixos níveis de bem-estar das populações, os lixões e os riscos que oferecem à saúde das gentes? Por que não discutir com os alunos a realidade concreta a que se deva associar a disciplina cujo conteúdo se ensina [...]. Por que não estabelecer uma "intimidade" entre os saberes curriculares fundamentais aos alunos e a experiência social que eles têm como indivíduos?

Nos espaços públicos educativos, particularizando neste estudo os docentes da Educação de Jovens e Adultos, se observa a convivência de normas institucionais propostas pelas chamadas "autoridades educacionais" com os saberesfazeres construídos pelos docentes a partir de vivências compartilhadas que fogem ao que secretarias e equipes pedagógicas propõem como normas pedagógicas a serem seguidas. A orientação pedagógica para o trabalho com estes educandos exige de seus professores não apenas a percepção do senso comum, para que seja contextualizada a realidade destes, mas um novo olhar, uma escuta sensível para que se entenda o que e como 
pensam estes sujeitos, o que os motiva a vir para a escola e, evidentemente, um aprofundamento teórico-conceitual que lhes permita transitarem pelos saberes ditos científicos e os populares e tecerem com seus educandos novos e significativos conhecimentos.

Gaudiano (2006, p. 108) contribui para que se compreenda esta tensão ao citar como categoria analítica a tática intersticial, para se referir ao conjunto de práticas empregadas por pessoas envolvidas em uma luta para abrir espaço ou afirmar sua existência, destacando que estas:

não são necessariamente deliberadas e planejadas, após seleção cuidadosa de estratégias relacionadas a objetivos discutidos e consensuais por uma comunidade, mas, em algumas ocasiões são formas dispersas e fragmentárias de proceder, como forma de sobrevivência ou como improvisação engenhosa.

Os docentes da Educação de Jovens e Adultos quando procuram resolver os desafios no coletivo, no diálogo, estão formulando uma prática pedagógica construída no próprio processo como uma tática que objetiva legitimar o outro como um legítimo outro (MATURANA, 2005) de modo a que o educando se empodere e se perceba como cidadão ativo e crítico capaz de influenciar seu destino e o de outros sujeitos em busca de uma sociedade igualitária e sustentável.

O processo de formação docente que se coloca para aprofundar uma discussão diferenciada foge ao lugar comum, exigindo para compreendê-lo um posicionamento libertário, que supere as amarras metodológicas - um pensamento complexificador em uma oposição consciente ao paradigma da simplificação (MORIN, 2007, p.13-14).

A complexidade nos obriga a termos dificuldade de permanecermos no interior de conceitos claros, distintos e fáceis para conceber a ciência, o conhecimento, o mundo em que estamos e a relação sujeito-mundo, pois não há uma ciência pura, uma lógica pura ou um pensamento puro (MORIN, 2007).

Neste sentido, para explicitar como está sendo constituído este processo autoformativo docente é necessário reafirmar que estas professoras ao romper com os velhos paradigmas tecnicistas ou psicologistas, fugindo ao comodismo do que já está posto, pronto, definido quando procuram criar uma prática própria, não exatamente inovadora, mas que atenda às reais necessidades de seus alunos estão valorizando/evidenciando as marcas de repertório identitáriocultural de seus educandos/suas educandas. Trazem em suas narrativas as redes de contextos (TRISTÂO, 2004, 2007) que criam e/ou se inserem.

Em nome da coerência não pretendo fixar-me em uma possibilidade de compreensão metodológica, mas trazer a este trabalho aportes teóricos que se aproximem. Remeto-me, então, a Sousa Santos (2007b, p.118) que fala sobre uma ecologia de saberes, de uma fuga ao conhecimento-regulação, que pode Revbea, São Paulo, V. 12, № 2: 274-283, 2017. 
ser compreendida como o movimento de fuga dos docentes ao instituído em defesa de um conhecimento-emancipação.

[...] próprio da ecologia de saberes constituir-se através de perguntas constantes e respostas incompletas. Aí reside a sua característica de conhecimento prudente. A ecologia de saberes capacita-nos para uma visão mais abrangente daquilo que conhecemos, bem como do que desconhecemos, e também nos previne para que, aquilo que não sabemos é ignorância nossa, não ignorância em geral.

Sousa Santos (2007a) destaca que "a abordagem cartográfica parte do postulado de que os interesses grupais ou de classe fazem acontecer tudo, mas não explicam nada" (p. 223), porque a explicação nunca explica o que acontece, mas o como acontece.

Compreendi, então, que para penetrar no emaranhado de dados produzidos seja importante fazer as perguntas adequadas, perceber que não existem respostas para todas elas, partir do princípio da incompletude. Isto me leva a dialogar mais uma vez com Freire $(2003$, p.53) que apresenta a ideia da consciência do inacabamento do ser humano na reflexão abaixo:

Gosto de ser gente porque inacabado sei que sou um ser condicionado, mas consciente do inacabamento, sei que posso ir mais além dele. [...] Gosto de ser gente porque, como tal, percebo afinal que a construção de minha presença no mundo, que não se faz no isolamento, isenta da influência das forças sociais, que não se compreende fora da tensão entre o que herdo geneticamente e o que herdo social, cultural e historicamente tem muito a ver comigo mesmo.

Utilizando as narrativas dos sujeitos praticantes, e algumas imagens fotográficas, procurei compor o universo da pesquisa porque a "[...] a fotografia pode revelar e desvelar as imagens do cotidiano da escola, do bairro, da comunidade, do meio ambiente e da vida cotidiana no processo aprenderensinar a "ver", em vez de simplesmente "olhar" as coisas" (TRISTÃO; NOGUEIRA, 2009). 
Pitadas de narrativas: para envolver o leitor...

Caminante no hay camino, se hace camino al andar...

Antonio Machado

Algumas falas bastante significativas dos sujeitos praticantes desta pesquisa - professoras e estudantes - permitem compreender sua tessitura:

- Às vezes, o trabalho aqui deixa a gente desanimada, esta coisa de inovar, de buscar o conhecimento no aluno, parece que estamos indo contra a corrente, dá vontade de desistir, mas quando a gente volta no dia seguinte $e$ percebe que alguns, não todos, nos dão uma resposta positiva, faz a gente querer ficar aqui juntas e lutar (fala condensada das professoras J. e C. em junho/2008, em um Grupo de Estudos na Escola Santo Amaro, Xerém).

- Eu vim para a escola porque quero aprender a ler, para ler a Bíblia e ver se o que os pastores (líderes religiosos) dizem que devo fazer está escrito lá. Cada um diz uma coisa. Eu quero saber. Acho que aqui eu vou aprender. A professora gosta da gente e disse que eu já sei muita coisa (fala da aluna V., aluna da turma de Alfabetização, em março/2009).

- Parabéns por terem tido esta ideia. Hoje eu aprendi, deste jeito diferente, muito mais coisas do que nos outros dias de aula... (Comentário feito pelo aluno J., 53 anos, da turma 104, à Orientadora Pedagógica da escola, no dia 5 de junho de 2009, Dia do Meio Ambiente, após assistir ao júri simulado feito por alunos e alunas da turma 503 da EJA).

\section{Considerações finais}

Este trabalho apresenta a tessitura de uma pesquisa voltada a compreender como se constitui um movimento instituinte de autoformação coletiva docente em que há sintonia e sinergia de seus sujeitos praticantes, no qual a Educação Ambiental é apresentada aos educandos e educandos de forma reflexiva e focada no aspecto vivencial.

Embora a orientação pedagógica para o trabalho com a Educação de Jovens e Adultos se volte necessariamente para a perspectiva freireana, traduzi-la para o espaçotempo atual exige uma postura docente reflexiva e autônoma, de modo a fazer escolhas coerentes e não apenas seguir uma metodologia. Entendemos que o teórico da prática - Paulo Freire - criou uma epistemologia, uma teoria do conhecimento, e não um método, que permite perceber o que está sendo "escrito" amorosamente no espaço educativo escolar e em seu entorno, pois a influência da escola ultrapassa seu limite espacial.

Esta postura crítica e acolhedora supera a ação pedagógica rotineira que envolve apenas o planejar e executar, e, exercita, efetivamente, a prática 
de construção coletiva que aponta para a formação em serviço como prática escolar que pode ser amparada em uma proposta de autoformação coletiva, na qual a autorreflexão deva se constituir em postura permanente.

A Educação Ambiental praticada de forma dialógica, compreensiva e amorosa permite investir na formação de sujeitos não-dicotômicos, plenos e conscientes de seu papel no Planeta.

Referências

ALVES, N.; GARCIA, R.L. (orgs.). O sentido da escola. Petrópolis: DP et Alii,2008.

CERTEAU, M. A invenção do cotidiano: 1. artes de fazer. Petrópolis, RJ: Vozes, 2008.

FREIRE, P. Pedagogia da autonomia: saberes necessários à prática educativa. Rio de Janeiro: Paz e Terra, 2003.

GAUDIANO, E.J.G. Configuración y significado: Educación para EI desarrollo sustentable. Trayectorias. Año VIII, num. 20-21, p. 100-108, eneroagosto, 2006.

HALL, S. A identidade cultural na pós-modernidade. Rio de Janeiro: DP\&A, 2006.

LINHARES, C.; LEAL, M. C. Formação de professores: uma crítica à razão e à política hegemônicas, Rio de Janeiro: DP\&A, 2002.

MATURANA, $H$. Emoções e linguagem na educação e na política. Belo Horizonte: UFMG, 2005.

MORIN, E. Introdução ao pensamento complexo. Porto Alegre: Sulina, 2007. PASSOS, L.A.; SATO, M. Estética da Carta da Terra: pelo prazer de (na tensividade) com-viver com a diversidade! In: RUSCHEINSKY, A. (Org.) Educação ambiental: abordagens múltiplas. Porto Alegre: Artmed, 2002.

PÉREZ, C.L.V. Cotidiano: história(s), memória e narrativa: Uma experiência de formação continuada de professoras alfabetizadoras. In GARCIA, R. L.(org.). Método: pesquisa com o cotidiano. RJ: DP\&A, 2003.

SOUSA SANTOS, B. A crítica da razão indolente: contra o desperdício da experiência. Para um novo senso comum: a ciência, o direito e a política na transição paradigmática. Volume 1. São Paulo: Cortez, 2007a.

SOUSA SANTOS, B. Renovar a teoria crítica e reinventar a emancipação social. São Paulo: Boitempo, 2007b.

TRISTÃO, M. A Educação ambiental e os contextos formativos na transição de paradigmas. ANPED: 2007.

TRISTÃO, M. A educação ambiental na formação de professores: redes de saberes. São Paulo: Annablume; Vitória: Facitec, 2004.

TRISTÃO, M.; NOGUEIRA, V. Educação Ambiental e suas relações com o universo da Fotografia, VITÓRIA, 2009.

UNESCO. Educação Ambiental: As grandes orientações da Conferência de Tbilisi. Brasília, 1997. 